\title{
O TERAPÊUTICO E O ANALÍTICO EM FREUD
}

\author{
Vinicius Anciães Darriba ${ }^{1}$ \\ Universidade do Estado do Rio de Janeiro, Rio de Janeiro-RJ, Brasil. \\ Carolina Bosse \\ Universidade Federal do Paraná, Curitiba-PR, Brasil.
}

\begin{abstract}
RESUMO. Este artigo tem como objetivo investigar, na obra de Freud, a demarcação que se institui entre o terapêutico e o analítico. Tal investigação enfoca, primeiramente, a passagem da hipnose à associação livre e o direcionamento do autor à questão da causa, o que estabelece uma visada para a cura analítica em confluência com o que se desdobra da exploração do campo do inconsciente e da consideração de um domínio pulsional. Delimitados por esta via os objetivos terapêuticos e analíticos, interroga-se, em seguida, como a dimensão do terapêutico se veria reintroduzida nos termos da nova direção de cura proposta por Freud.
\end{abstract}

Palavras-chave: Freud; terapia; psicanálise.

\section{THE THERAPEUTIC AND THE ANALYTICAL IN FREUD}

\begin{abstract}
This article aimed to investigate into Freud's work the boundary between the therapeutic and analytical process. This research focuses mainly on the hypnosis's transition to free association; the author's aiming to a cause , which establishes a target for analytical treatment in confluence with the unfolding of the field of the unconscious investigation and instinctive consideration of a domain. Delimited, in this way, the therapeutic and analytical goals, questions then, how the therapeutic dimension would be reintroduced under the new direction of healing that is proposed by Freud.
\end{abstract}

Keywords: Freud; therapy; psychoanalysis.

\section{EL TERAPÉUTICO Y EL ANALÍTICO EN FREUD}

RESUMEN. Este artículo tiene como objetivo investigar, en la obra de Freud, la demarcación que establece entre la terapéutica y el analítico. Esta investigación se centra, en primer lugar, en el pasaje de la hipnosis a la libre asociación, en la canalización del autor a la pregunta de la causa, que establece una meta para la cura analítica hasta la confluencia con el que se desarrolla la explotación del campo del inconsciente y del examen de un campo pulsional. Delimitados, por esta vía, los objetivos terapéuticos y analíticos, se pregunta, entonces, como el terapéutico volverá a presentarse en la nueva dirección de cura que es propuesto por Freud.

Palabras-clave: Freud; terapia; psicoanálisis.

O termo "terapia" deriva da palavra grega therapeia, cujo significado remete a cuidado, atendimento e tratamento de doentes. Associando o terapêutico e o psíquico, Freud (1904/2006) afirma que o emprego da psicoterapia desde sempre esteve associado às práticas clínicas, sendo assim "a mais antiga terapia de que se serviu a medicina" (p.245), pois neste campo, com vistas à cura, induziam-se os doentes a um estado de "expectativa crédula" (Freud, 1904/2006, p.245), a fim de facilitar a adesão ao tratamento médico por meio de certa sugestão. Esta sugestão, segundo Freud (1916/2006), era "dirigida contra a manifestação dos sintomas", configurando uma luta entre a autoridade médica e "os motivos da doença" (p.449). Assim, a psicoterapia era empregada de modo a implementar o tratamento médico, em consonância com as palavras do antigo aforisma da medicina que prega: "Uma terapia ideal deve ser rápida, confiável e não

\footnotetext{
${ }^{1}$ Endereço para correspondência: Rua Marquês de São Vicente, 17, ap. 207, Gávea. CEP 22.451-041 - Rio de JaneiroRJ, Brasil. E-mail: vdarriba@centroin.com.br
} 
desagradável para o paciente ('cito, tuto, jucunde')" (Freud, 1916/2006, p.450).

Podemos observar que estavam de acordo com este ideal terapêutico os pressupostos do método hipnótico desenvolvido e empregado por Joseph Breuer, pois a hipnose se aproximava em muito da concepção clássica de um tratamento terapêutico: não exigia trabalho por parte do paciente e agia direta e unicamente na queixa posta, promovendo o rápido desaparecimento do sintoma em questão. Não obstante, embora a hipnose possibilitasse um rápido alívio, os dados clínicos comprovavam 0 insistente retorno de sintomas, mesmo que em diferentes apresentações. Desta forma, o tratamento hipnótico tornava a ser empregado, o que fazia do paciente "um viciado dessa espécie de terapia como se fosse um narcótico" (Freud, 1916/2006, p.450). Segundo Freud (1916/2006), para o praticante, o emprego da hipnose "era um trabalho braçal, não uma atividade científica, e lembrava magia, encantamento, truque de prestidigitador" (p.450).

Estas observações e críticas freudianas resultaram da experiência com o método hipnótico no tratamento das neuroses histéricas, um método que precedeu o desenvolvimento da psicanálise e cujo abandono inaugurou propriamente o campo analítico. Neste artigo examina-se em que termos Freud, em diferentes passagens de sua obra, contrapõe os objetivos terapêuticos e os fins que anuncia serem os do procedimento que inaugura: 0 da cura analítica. Esta diferenciação entre o terapêutico e 0 analítico figura desde seus primeiros textos, notadamente nos Estudos sobre a histeria (1893), até os derradeiros, entre os quais Análise Terminável e Interminável (1937) terá aqui lugar de destaque.

\section{DA HIPNOSE À ASSOCIAÇÃO LIVRE: A QUESTÃO DA CAUSA, O CAMPO DO INCONSCIENTE E A PREVALÊNCIA DO PULSIONAL}

Nos Estudos sobre a histeria (1893), escritos por Freud em coautoria com Breuer, encontra-se a observação de que o método hipnótico, empregado para o tratamento destes casos promove um efeito catártico no paciente "... ao permitir que seu afeto estrangulado encontre uma saída através da fala" (Breuer \& Freud, 1893/2006, p.52). Tratava-se então, como bem nomeara a mais famosa das pacientes do Dr. Breuer, de uma "talking cure" (Freud, 1910/2006, p.30). Para tanto, o método hipnótico era executado de modo a submeter a representação traumática em questão "à correção associativa ao introduzi-la na consciência normal (sob hipnose leve) ou eliminá-la por sugestão do médico" (Breuer \& Freud, 1893/2006, p.52). No referido texto Freud declara que cada sintoma é individualmente trabalhado em hipnose até seu desaparecimento, 0 que se daria através da descrição do fato em seus detalhes por parte do paciente e mediante a intervenção sugestiva do médico, promovendo sua extinção.

Assim, os resultados da aplicação do método hipnótico indicavam que a neurose histérica era constituída primordialmente por uma gênese traumática, invariavelmente de ordem sexual, segundo o que se repetia no relato das pacientes: a sedução exercida por um adulto em tempos remotos de sua infância. Concluiu-se daí que, para a maioria dos sintomas histéricos, as causas desencadeadoras deveriam residir em traumas psíquicos que não tiveram suficiente ab-reação, por conta justamente da precocidade do episódio de sedução descrito. Seria esta a razão pela qual, na histeria, as representações patológicas do evento em questão se manteriam inconscientes, com a acentuada intensidade afetiva que the era correspondente.

Não obstante, se neste escrito Freud anuncia a descoberta do mecanismo dos fenômenos histéricos, também testemunha a parcialidade do êxito terapêutico que obtinha com a sugestão. Observara a ação do tratamento recaindo unicamente sobre a queixa posta, sem possibilidade de avançar às razões etiológicas para a instauração dos sintomas. Por conseguinte, a hipnose mantinha o núcleo causal da neurose intacto e preservado, portanto realizava uma intervenção parcial. Como escreve Freud (Breuer \& Freud,1893/2006):

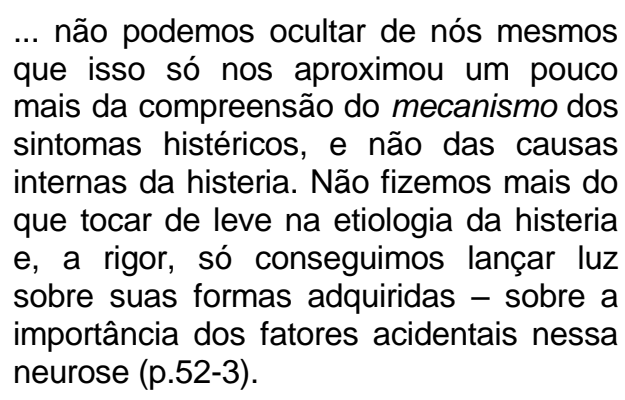

Assim, desde muito cedo o texto de Freud revela um interesse pela questão da causa. Neste sentido, pode-se aventar que sua curiosidade em relação à histeria estaria associada, em grande 
medida, ao enigma etiológico que esta propunha. Foi-lhe marcante constatar, como se verifica em sua referência frequente a isso, que, neste domínio, à investigação acerca da causa se tenha sobreposto o tratamento do sintoma; porém tal sobreposição não levou Freud a submeter a pesquisa sobre a causa à finalidade terapêutica.

Em um momento mais avançado de sua obra, quando respondeu aos que pleiteavam que a psicanálise figurasse como uma especialidade médica, testemunhou que, em seu caso, ter-se tornado médico representou um desvio de seu propósito original: "Não tenho conhecimento algum de haver tido qualquer anseio, na minha primeira infância, de ajudar a humanidade sofredora" (Freud, 1926/2006, p.243). Quanto a este dito propósito original, Freud (1926/2006) relatou que o que sentia em sua juventude era "uma necessidade absorvente de compreender algo dos enigmas do mundo em que vivemos" (p.243); mas este desejo de saber dirigido ao registro da causa em um terreno então desvalorizado pela medicina, o da clínica da histeria, acabou condicionando, neste terreno, a efetividade terapêutica. Freud (1926/2006) diria, ainda, não considerar que a ausência de um "autêntico temperamento médico" pudesse causar dano a seus pacientes, visto que "não é muito vantajoso para os pacientes se o interesse terapêutico do seu médico tiver uma ênfase emocional muito marcante" (p.243-4).

Dada a divergência entre seus horizontes de trabalho, a parceria de Freud com Breuer encerrouse logo após a publicação dos Estudos sobre a histeria (1893). Poucos anos depois, em carta endereçada a Wilhelm Fliess - médico especialista em nariz e garganta que, por conta da excentricidade de suas teorias, tornara-se depositário da confiança no acolhimento ao pioneirismo da psicanálise -, Freud (1950/2006) confidenciou-lhe as reviravoltas teóricas a que ele próprio havia chegado por meio de sua autoanálise, anunciando: "não acredito mais em minha neurótica" (p.309). Isto salientava certos empecilhos ao curso das análises desde o equivocado embasamento teórico que repousava na teoria da sedução e cuja crítica apontava em seguida: "em todos os casos, o pai, não excluindo o meu, tinha de ser apontado como pervertido" (Freud, 1950/2006, p.310). De fato, em outra carta a Fliess, Freud (1950/2006, p.281) havia proposto a histeria como sempre oriunda do contato com uma geração anterior perversa, afirmação que acabou constatando não ser pertinente.
Deste modo, o autor pôs-se a rever a hipótese de 0 acontecimento traumático operar como 0 exclusivo causador da neurose, e concluiu que "no inconsciente não há indicações da realidade, de modo que não se consegue distinguir entre a verdade e a ficção que é catexizada com o afeto" (Freud, 1950/2006, p.310). Esta nova compreensão abriu campo para a descoberta da sexualidade infantil em toda a sua amplitude como causada por ímpetos pulsionais, assim como para a concepção de realidade psíquica desde estas fantasias de sedução que recobririam o advento da própria sexualidade.

A constatação da prevalência das fantasias e dos conflitos pulsionais na neurose trouxe novas direções à teoria de Freud e obrigou-o, por consequência, a desenvolver e empregar um novo método no tratamento das neuroses, que abarcasse as considerações reformuladas. Se os primórdios da teoria psicanalítica caracterizam-se, neste sentido, pelo abandono da hipnose, Freud, ao fazê-lo, dava claros indícios de que esse abandono se associava a pretensões mais amplas concernentes à psicanálise - por exemplo, quando defendeu o método psicanalítico como aquele que poderia promover uma "cura radical" (Freud, 1905/2006, p.247), ao fazer uma alusão à terapia de Finsen para o lúpus. Por constatar a impossibilidade de "tornar a sugestão tão forte e sólida quanto seria necessário para obter a cura permanente" (Freud, 1905/2006, p.247), decidiu pelo abandono do antigo método. Concomitantemente, via-se despontar uma direção para a cura que se estendia para além da expectativa, pela mera supressão dos sintomas, ficando mais evidente que o trabalho analítico que Freud almejava não se validaria estritamente por sua dimensão terapêutica.

Inferindo da observação clínica que um núcleo patológico se estendia para além do sintoma nos distúrbios neuróticos, o autor desenvolveu e estabeleceu a associação livre como método a ser empregado no tratamento desses distúrbios, de modo que se pudessem contemplar exigências agora mais vastas, abarcando o campo pulsional e a trama psíquica que aí se inclui. Para tanto, era pedido ao paciente que assumisse o compromisso de relatar ao médico todos os conteúdos que the ocorressem à mente, sem exercer sobre eles nenhuma censura ou restrição de valor moral, incluindo em sua fala mesmo aqueles que se impusessem como insensatos ou irrelevantes. A implementação de tal método permitiu a Freud (1923/2006) afirmar: 
Quando a "regra fundamental da psicanálise", que acaba de ser enunciada, era obedecida, o curso da associação livre produzia um estoque abundante de idéias que podiam nos colocar na pista daquilo que o paciente havia esquecido. Com efeito, esse material não trazia à tona o que realmente fora esquecido, mas trazia tão claras e numerosas alusões a ele que, com o auxílio de certa suplementação e interpretação, o médico podia adivinhar (ou reconstruir) o material esquecido a partir dele (p.220).

O método analítico diferenciava-se, assim, da clássica compreensão do que seria uma terapia, pelo fato de não veicular uma proibição médica, ainda que sugestiva, sobre a manifestação sintomática. Tampouco apoiava-se no "consolo corriqueiro, que tão liberalmente dispensamos aos enfermos - 'Você logo ficará bom de novo!" (Freud, 1904/2006, p.246). Ao contrário, ao paciente eram apresentadas, às claras, as condições previstas para o acesso à cura:

\begin{abstract}
Mostramos-Ihe as dificuldades do método, sua longa duração, os esforços e os sacrifícios que exige; e, quanto a seu êxito, Ihe dizemos não nos ser possível prometê-lo com certeza, que depende de sua própria conduta, de sua compreensão, de sua adaptabilidade e de sua perseverança (Freud, 1915/2006, p.25).
\end{abstract}

A associação livre colocava o paciente a trabalhar em busca das causas de sua afecção e assim the exigia um grande investimento na superação das forças de resistência para a revelação do conteúdo recalcado. Em contrapartida, também exigia 0 equivalente dispêndio de investimentos por parte do praticante. Segundo Freud (1923/2006), era como se o "trabalho houvesse ficado mais difícil e complicado; no entanto, o lucro inestimável estava em que se obtinha agora uma compreensão interna (insight) de uma ação recíproca de forças que haviam estado ocultas do observador pelo estado hipnótico" (p.220).

Ele notara, a partir da experiência com a hipnose, que os fatos ocorridos e implicados na causação da doença apenas aparentemente estavam esquecidos, pois, ainda que estes conteúdos estivessem afastados da consciência, mantinham-se ativos e operantes em outro campo: o inconsciente. Esta descoberta foi o que the permitiu prescindir de tal método, constatação a que se somava a conclusão de que a sugestão "não elimina a resistência, apenas a evade, com o que fornece tão somente dados incompletos e resultados passageiros" (Freud, 1905/2006, p.239). Com a associação livre, em contrapartida, "tratavase de fazer o doente contar aquilo que ninguém, nem ele mesmo, sabia" (Freud, 1910/2006, p.38), de modo a revelar conteúdos inconscientes que permitiriam aceder ao porte e à permanência da cura que se almejava.

A opção pela associação livre baseou-se, deste modo, no reconhecimento do valor das "ideias inintencionais" (Freud, 1904/2006, p.238), pela observação de que estas guardavam relação com a origem do conteúdo recalcado e assim se tornavam caras à psicanálise, na medida em que preservavam em seu bojo a gênese do conflito entre as aspirações egoicas e as moções pulsionais que causavam a neurose. A adoção de um método que contempla este campo indicou um novo caminho na doutrina freudiana, além do restabelecimento do paciente; "Quando se dispõe de um procedimento que permite avançar das associações até o recalcado, das distorções até o distorcido, pode-se também tornar acessível à consciência o que era antes inconsciente na vida anímica" (Freud, 1904/2006, p.328). Era este o novo horizonte que se impunha à psicanálise.

Os objetivos de Freud já não se restringiam a remover o sintoma, ao contrário, ele buscava promover uma profunda alteração psíquica no paciente. Nos textos em que introduziu o novo método como sendo a via pela qual se alcançariam estas conquistas, Freud (1905/2006) defendeu-o pelo fato de ser "o mais penetrante, o que chega mais longe, aquele pelo qual se consegue a transformação mais ampla do doente" (p.246). Em 1916 voltou a insistir na diferença entre a hipnose e a associação livre, nos seguintes termos:

O tratamento hipnótico procura encobrir e dissimular algo existente na vida mental; o tratamento analítico visa a expor e eliminar algo. O primeiro age como cosmético, o segundo, como cirurgia. $\mathrm{O}$ primeiro utiliza-se da sugestão, a fim de proibir os sintomas: fortalece as repressões, mas afora isso, deixa inalterados todos os processos que levaram à formação dos sintomas. O tratamento analítico faz seu impacto mais retrospectivamente, em direção às raízes, onde estão os conflitos que originaram os sintomas, e utiliza a sugestão a fim de 
modificar o resultado desses conflitos. O tratamento hipnótico deixa o paciente inerte e imodificado, e, por esse motivo também, igualmente incapaz de resistir a alguma nova oportunidade de adoecer. Um tratamento analítico exige do médico, assim como do paciente, a realização de um trabalho sério, que é empregado para desfazer as resistências internas. Através da superação dessas resistências, a vida mental do paciente é modificada permanentemente, é elevada a um alto nível de evolução e fica protegida contra novas possibilidades de adoecer. (Freud, 1916/2006, p.451).

Assim, o emprego da associação livre possibilitava à psicanálise debruçar-se sobre o conflito pulsional que subjaz ao recalque e sobre as fantasias e produções do inconsciente que daí derivavam enquanto trama psíquica, a fim de promover a mudança almejada. Se, por um lado, ao visar à causa das neuroses, Freud postulava uma clínica que, além de preencher lacunas da memória e esclarecer efeitos enigmáticos da doença, pudesse alcançar objetivos ainda mais ambiciosos, por outro, a nova formulação colocava0 diante de impasses igualmente mais desafiadores. Escreve:

\begin{abstract}
... trata-se de tornar 0 inconsciente acessível à consciência, que se consegue mediante a superação das resistências. Mas não se deve esquecer que tal estado tampouco se apresenta no ser humano normal, e que só raramente fica-se em condições de levar o tratamento a um ponto que se aproxime disso (Freud, 1910/2006, p.239).
\end{abstract}

A dificuldade no caminho da psicanálise, por consequência, já não consistia mais na indução do paciente à hipnose, mas sim, em sobrepujar as forças internas que se opunham à revelação do material esquecido, as quais, mantendo-se inconscientes, cultivavam também a permanência do sintoma e da condição neurótica do paciente. Desta feita, conclui que "a força que mantinha o estado mórbido fazia-se sentir como resistência do enfermo" (Freud, 1910/2006, p.39). Freud pretendia desvelar esta resistência com o emprego da associação livre, que ele intuía se estender em declinações ainda mais sérias ao tratamento; uma vez que podia agora notar que "os doentes se aferram a sua doença, chegando, em função disso, a lutar contra sua própria recuperação" (Freud,
1910/2006, p.247) - fato enigmático que lançava o autor a pesquisas mais extensas a respeito dos caminhos para operar a mudança radical que ambicionava com sua psicanálise.

Ao tomar a sério tal enigma, podemos considerar que Freud se desvencilhou do pressuposto terapêutico segundo o qual o sujeito quer o próprio bem, aquele que a intervenção terapêutica lhe reservaria. A psicanálise assume, com ele, o ônus de uma verdade que aí concerne seja à divisão do inconsciente seja a uma esfera do pulsional que atenta contra a autonomia do psíquico; verdade analítica que diverge do que, em grande medida, embasa o terapêutico. Assim sendo, Freud anteviu em sua doutrina um obstáculo que ia além do deciframento dos enigmas incluídos nas formações sintomáticas, do desvelamento da cena traumática ou dos jogos de condensação e deslocamento das produções inconscientes. Tratava-se, antes de tudo, de encontrar meios de ultrapassar limites ainda maiores, ou seja, as resistências de uma força psíquica que tornava imperiosa sua satisfação, ainda que ao preço do sofrimento do próprio doente e do fracasso na cura.

Temos, assim, que, devido à peculiaridade e às altas exigências de tal método, a possibilidade de sua aplicação torna-se menos universal do que as promessas associadas às vias terapêuticas. Freud indicou estar seu emprego restrito a certa classe de pessoas. A temática da aplicabilidade da psicanálise, que nos primórdios (Freud, 1893) se reportava à questão diagnóstica quanto à exclusividade da histeria como indicação do tratamento, enunciava-se agora em outros termos. Segundo Freud (1903/2006), as pessoas analisáveis deveriam contar com "certo grau de inteligência natural e de desenvolvimento ético", uma vez que, "com pessoas sem nenhum valor, o médico logo perde o interesse que lhe permite aprofundar-se na vida anímica do doente" (p.240).

No intuito de ler o que Freud aqui pontua em termos outros que o de atributos que distinguiriam as pessoas, podemos tomar a dimensão do aprofundar-se na citação anterior como se referindo a certa implicação necessária àquele que se dispõe ao trabalho analítico. Esta implicação e esta responsabilidade seriam condições para 0 emprego do método não passíveis de serem colocadas segundo agrupamentos de pessoas. Só seria verificável na perspectiva de cada um, em oposição às categorizações que buscam tudo 
subsumir. Não por acaso, na citação abaixo, ao se referir aos que seriam imprestáveis para a análise, Freud (1904/2006) falou dos indivíduos que tudo atribuem à doença:

\begin{abstract}
... deve-se reparar no valor da pessoa em outros aspectos e recusar os pacientes que não possuam certo grau de formação e um caráter razoavelmente digno de confiança. Não se deve esquecer que há também pessoas sadias que não prestam para nada, e que com excessiva facilidade, em se tratando desses indivíduos de valor reduzido, tende-se a atribuir à doença tudo o que os incapacita para a existência, quando lhes ocorre mostrar algum laivo de neurose (p.250).
\end{abstract}

Observamos, assim, os esforços freudianos em discernir as condições, os objetivos e os obstáculos em relação aos meios para atingir a devida consistência e permanência dos efeitos conquistados em uma análise. Estando esses associados à busca pela construção de um novo estado psíquico, definiu-se uma nova visada de cura, a cura analítica, remetida para além do restabelecimento do estado anterior ao sintoma, o que poderia ser obtido com a sugestão terapêutica por meio da hipnose. Se no método hipnótico o sucesso terapêutico estava associado à sugestão do médico, ao coibir as manifestações sintomáticas, na psicanálise

\begin{abstract}
A parte decisiva do trabalho se consegue criando na relação do paciente com o médico - na transferência - novas edições dos antigos conflitos; nestas, o paciente gostaria de se comportar do mesmo modo como o fez no passado, ao passo que nós, concentrando todas as forças mentais disponíveis [do paciente], compelimo-lo a chegar a uma nova decisão. Assim, a transferência torna-se o campo de batalha no qual todas as forças mutuamente em choque se enfrentam" (Freud, 1916/2006, p.455).
\end{abstract}

Nas terapias que se servem de sugestão, "a transferência é cuidadosamente preservada e mantida intocada" (Freud, 1916/2006, p.453-4), ao passo que, "na análise, a própria transferência é sujeita a tratamento, e é dissecada em todas as formas sob as quais aparece" (Freud, 1916/2006, p.454). O final de uma análise coincidiria, assim, com a própria dissolução da transferência, subsistindo os resultados finais de uma modificação interna no paciente fora do alcance da influência do praticante.

Se, por um lado, Freud esforçava-se por demonstrar as diferenças que o método analítico guardava para o hipnótico ou para aquilo que, nos termos de uma clínica médica, seria reconhecido como uma terapia ideal por outro ele admitia a necessidade prevalente de efeitos derivados da terapêutica. Como esta vertente terapêutica poderia ainda se coadunar com os objetivos de uma cura radical que, a fim de promover a conquista de um novo estado psíquico, se sobrepunha e ultrapassava a visada de um restabelecimento sintomático? Em que medida seria possível articulá-la em acordo com os pressupostos analíticos que Freud avançou? Seguiremos com estas questões.

\section{A CURA ANALÍTICA E O TERAPÊUTICO}

Em Analise terminável e interminável (1937), Freud consolidou esta concepção de cura que ultrapassa as intenções de restabelecimento do doente, as quais se restringiriam à supressão de manifestações patológicas de caráter neurótico. Trata-se, como vimos, de uma visada para a cura que já se enunciava desde o abandono da hipnose pela adoção da associação livre, com o que a psicanálise não só passou a se dirigir à remissão sintomática, mas abriu-se aos efeitos de maior amplitude implicados na busca pela causa. No referido texto Freud discorreu sobre os alcances da clínica psicanalítica, bem como sobre os obstáculos implicados na cura. Foi no cerne desta temática que, zelando pela diferenciação dos objetivos terapêuticos e analíticos, o autor questionou em que, então, consistiria propriamente a terminabilidade de uma análise.

Do lado dos objetivos terapêuticos, o êxito do tratamento estaria, segundo o autor, na superação de sintomas, inibições e anormalidades neuróticas. Para o cumprimento desta meta, é preciso que o analista considere ter advindo à consciência suficiente material recalcado - por meio de um trabalho de recordação e elaboração - a ponto de se exaurir a possibilidade de retorno da sintomatologia em questão. Para que, neste primeiro momento, tais objetivos se efetivassem, a psicanálise visaria transpor as resistências do eu, a fim de preencher as lacunas da lembrança que foram censuradas.Não obstante, é além desta visada, mas sem que dela se possa prescindir, que, no mesmo escrito, Freud avançou, apresentando 
uma nova versão para o fim de uma análise, uma versão concernente à didática, na qual o analisando em questão é candidato à prática. Por exceder aos objetivos terapêuticos, Freud (1937/2006) a considerava mais ambiciosa do que a primeira, pois, nestes casos, a análise exerceria "uma influência de tão grande consequência sobre o paciente, que não se pode esperar que nenhuma mudança ulterior se realize neste, caso sua análise venha a ser continuada" (p.235).

De acordo com 0 autor, o intuito dos candidatos à análise didática era erradicar a possibilidade de não só de retornar o mesmo sintoma que outrora o levara à busca de tratamento, mas também de exaurir-se qualquer outra propensão à doença, através de uma profunda alteração de sua personalidade, promovida pelo trabalho analítico junto às raízes de suas resistências, visando ao recalque original. Segundo Freud (1937/2006), "a façanha real da terapia analítica seria a subsequente correção do processo original de repressão, correção que põe fim à dominância do fator quantitativo" (p.243).

Desta forma, seria possível alcançar o que o autor (Freud, 1937/2006) definiu como um "amansamento", no qual a pulsão é posta "completamente em harmonia com o ego ... e não mais busca seguir seu independente caminho para a satisfação" (p.241). Tal "amansamento" consistiria em a análise promover uma retificação no regime de satisfações, de modo a viabilizar a sublimação enquanto vicissitude pulsional. Assim, a perícia de uma análise, segundo Freud (1937/2006), estaria em fornecer subsídios para que se opere uma retificação nas antigas repressões, das quais "algumas são demolidas, ao passo que outras são identificadas, mas construídas de novo, a partir de material mais sólido" (p.243) - material mais sólido, diríamos, do que o não saber promovido pelo recalque e a não responsabilização pela satisfação que aí se cunha.

Ainda segundo o autor (1937/2006), trata-se da construção de um estado psíquico absolutamente novo, sendo a mais íntima reivindicação de sua teoria "o fato de que a análise produz um estado que nunca surge espontaneamente no ego e que esse estado recentemente criado constitui a diferença essencial entre uma pessoa que foi analisada e outra que não o foi" (p.242). Para tanto, o fim de uma análise incluiria entre suas exigências uma firme convicção na existência do inconsciente, a ponto de capacitar o analisando em questão "a perceber em si mesmo coisas que de outra maneira seriam inacreditáveis para ele", contandose com que "... os estímulos que recebeu em sua própria análise não cessem quando esta termina, com que os processos de remodelamento do ego prossigam espontaneamente no indivíduo analisado, e com que se faça uso de todas as experiências subsequentes nesse recém-adquirido sentido (Freud, 1937/2006, p.265)".

Nestes termos, uma análise alcançaria seu término nos objetivos terapêuticos, porém lançarse-ia ao interminável, como refere Freud, no ponto em que concerniria à preparação do analista. $\mathrm{O}$ que, no entanto, produziria um avanço desta espécie? $O$ que promoveria um alcance de tão grande porte, em que não seria a questão terapêutica que guiaria um trabalho tão incessante e minucioso de análise? Enfim, Freud interrogou-se sobre uma direção no trabalho da análise que não se reduziria ao terapêutico, o que remete a outra questão: a que diz respeito ao lugar do terapêutico na análise.

De acordo com as compilações das atas da sociedade psicanalítica de Viena, Freud (Federn \& Nunberg, 1979) teria afirmado, em uma das célebres reuniões das quartas-feiras, que "o neurótico só está doente na medida em que sofre: é aí onde a terapia encontra limites. A terapia pode curar o neurótico na medida em que sofre; na medida em que não sofre, a terapia é ineficaz" (p.120). Ainda assim, em suas Recomendações aos médicos, o autor (Freud, 1912/2006) advertia sobre os perigos da "ambição terapêutica" (p.128). Em vários momentos especificou que "o tratamento analítico deve ser efetuado, na medida do possível, sob privação - num estado de abstinência" (Freud, 1918/2006, p.176). Isto implica que, "cruel como possa parecer, devemos cuidar para que o sofrimento do paciente, em um grau de um modo ou de outro efetivo, não acabe prematuramente" (Freud, 1918/2006, p.176).

Essencialmente, Freud (1918/2006) observou que os pacientes estavam sempre prontos a se apaziguarem em soluções incompletas, e que então se correria o perigo de jamais conseguir senão melhoras insignificantes e transitórias (p.176). Alertou, inclusive, que mesmo na análise podem ser buscadas satisfações substitutivas deste tipo, por meio da relação transferencial com o analista. Desta forma, o sofrimento passa não apenas a figurar como a causa de um pedido de ajuda, sendo o que leva alguém a se reportar a um analista, mas também a constituir-se como o próprio empuxo motor do trabalho analisante. 
Sendo assim, quanto ao sofrimento causado pelos sintomas, "devemos remontar às suas origens, devemos reconstituir o conflito do qual eles surgiram e, com o auxílio das forças motrizes que, no passado, não estavam à disposição do paciente, devemos conduzir o conflito rumo a um resultado diferente" (Freud, 1916/2006, p.454-5). Com isto, Freud (1918/2006) justificava o nome de sua prática pelo fazer que ela pressupunha:

\begin{abstract}
Por que "análise" - que significa dividir ou separar, sugere uma analogia com o trabalho, levado a efeito pelos químicos, com substâncias que encontram na natureza e trazem para os seus laboratórios? Porque, em um importante aspecto, existe realmente uma analogia entre os dois trabalhos. Os sintomas e as manifestações patológicas do paciente, como todas as suas atividades mentais, são de natureza altamente complexa; os elementos desse composto são, no fundo, motivos, impulsos instintuais. O paciente, contudo, nada sabe a respeito desses motivos elementares, ou não os conhece com intimidade suficiente. Ensinamo-lo a compreender a maneira pela qual essas formações mentais altamente complicadas são compostas; remetemos os sintomas aos impulsos instintuais que os motivaram; assinalamos ao paciente esses motivos instintuais, que estão presentes em seus sintomas, e dos quais até então não tinha consciência - como - químico que isola a substância fundamental, o 'elemento' químico, do sal em que ele se combinara com outros elementos e no qual era irreconhecível (p.173).
\end{abstract}

Apesar disso, sublinhava a constante "preocupação de que o paciente recebe análise demais e muito pouca síntese" (Freud, 1918/2006, p.174). Nesta última, talvez residisse a fonte de um efeito terapêutico que repousaria na "restauração de algo que foi destruído - destruído, por assim dizer, pela vivissecção" (Freud, 1918/2006, p.176). O que é isto que se colocaria no lugar? O que é isto que se orientaria pela cura analítica e do qual derivaria também o efeito terapêutico? Afirma Freud (1918/2006): "Analisamos o paciente - isto é, dividimos os processos mentais em seus componentes elementares e demonstramos esses elementos instintuais nele, isoladamente; o que seria mais natural do que esperar que também o ajudemos a fazer uma nova e melhor combinação deles?" (p.176)
Podemos entender 0 que se refere à terapêutica pela breve ilustração que ele dá em uma passagem de um caso clinico:
$\mathrm{Na}$ sessão seguinte, o paciente mostrou grande interesse por aquilo que eu dissera, mas se arriscou, conforme me contou, a apresentar algumas dúvidas. - Como, perguntou, podia justificar-se a informação de que a autocensura, o sentimento de culpa, tenha um efeito terapêutico? - Expliquei que não era a informação que possuía esse efeito, mas sim a descoberta do conteúdo inconsciente ao qual a autocensura de fato estava ligada (Freud, 1909/2006, p.157).

Isto significa que os benefícios buscados no âmbito terapêutico são alcançados como consequência do processo analítico, um processo que visa à cura. Vê-se que "favorecer a fala de quem sofre tem, portanto, um efeito terapêutico inegável" (Fingermann, D \& Dias, M. M., 2005, p.48); porém, diferentemente de uma terapêutica que se posiciona alheia à questão da causa, a psicanálise visa à diminuição do sofrimento como consequência de uma direção clínica que visa à cura. O terapêutico ocorre, assim, em uma análise, como efeito secundário das conquistas alcançadas em um processo de cura, na medida em que o sofrimento, enquanto empuxo motor, pode ser gradativamente substituído por certo "querer saber" acerca da questão da causa.

\section{REFERÊNCIAS}

Breuer, J. \& Freud, S. (2006) Estudos sobre a histeria. (V. Ribeiro, Trad.). Em J. Salomão (Org.), Edição standard brasileira das obras psicológicas completas de Sigmund Freud. (Vol. 2, pp. 13 - 318) Rio de Janeiro: Imago. (Original publicado em 1893)

Federn, E. \& Nunberg, H. (1979). Actas de la Sociedad Psicoanalitica de Viena: las reuniones de los miercoles. Buenos Aires: Nueva Visión.

Fingermann, D.\& Dias, M. M., (2005) Por causa do pior. São Paulo: Iluminuras.

Freud, S. (2006) O método psicanalítico de Freud. (V. Ribeiro, Trad.). Em J. Salomão (Org.), Edição standard brasileira das obras psicológicas completas de Sigmund Freud. (Vol. 7, pp. 234 240) Rio de Janeiro: Imago. (Original publicado em 1904)

Freud, S. (2006). Sobre a psicoterapia. (V. Ribeiro, Trad.). Em J. Salomão (Org.), Edição standard brasileira das obras psicológicas completas de 
Sigmund Freud. (Vol. 7, pp. 242 - 254). Rio de Janeiro: Imago. (Original publicado em 1905)

Freud, S. (2006) Notas sobre um caso de neurose obsessiva. (J. Salomão, Trad.). Em J. Salomão (Org.), Edição standard brasileira das obras psicológicas completas de Sigmund Freud. (Vol. 10, pp. 135 - 275) Rio de Janeiro: Imago. (Original publicado em 1909)

Freud, S. (2006) Cinco lições de psicanálise. (J. Salomão, Trad.). Em J. Salomão (Org.), Edição standard brasileira das obras psicológicas completas de Sigmund Freud. (Vol. 11, pp. 15 73) Rio de Janeiro: Imago. (Original publicado em 1910)

Freud, S. (2006) Recomendações aos médicos. (J. Salomão, Trad.). Em J. Salomão (Org.), Edição standard brasileira das obras psicológicas completas de Sigmund Freud. (Vol. 12, pp. 121 133) Rio de Janeiro: Imago. (Original publicado em 1912)

Freud, S. (2006) Conferência I - Introdução (J. Salomão, Trad.). Em J. Salomão (Org.), Edição standard brasileira das obras psicológicas completas de Sigmund Freud. (Vol. 15, pp. 25 89) Rio de Janeiro: Imago. (Original publicado em 1915)

Freud, S. (2006) Conferência XXVIII A terapia analítica. (J. Salomão, Trad.). Em J. Salomão (Org.), Edição standard brasileira das obras psicológicas completas de Sigmund Freud. (Vol. 16, pp. 242 - 254) Rio de Janeiro: Imago. (Original publicado em 1916).

Freud, S. (2006) Linhas de progresso na terapia analítica. In S. Freud, Edição standard brasileira das obras psicológicas completas de Sigmund Freud. (J. Salomão, trad., Vol. 17, pp.
169 - 182) Rio de Janeiro: Imago. (Original publicado em 1918)

Freud, S. (2006) A questão da análise leiga: conversações com uma pessoa imparcial. In S. Freud, Edição standard brasileira das obras psicológicas completas de Sigmund Freud. (J. Salomão, trad., Vol. 20, pp. 173 - 241) Rio de Janeiro: Imago. (Original publicado em 1926)

Freud, S. (2006) Análise terminável e interminável. In S. Freud, Edição standard brasileira das obras psicológicas completas de Sigmund Freud. (J. Salomão, trad., Vol. 23, pp. 231 - 270) Rio de Janeiro: Imago. (Original publicado em 1937)

Freud, S. (2006) Extratos dos documentos dirigidos a Fliess. In S. Freud, Edição standard brasileira das obras psicológicas completas de Sigmund Freud. (J. Salomão, trad., Vol. 1, pp. 221 - 330) Rio de Janeiro: Imago. (Original publicado em 1950).

Recebido em 26/07/2012 Aceito em 25/02/2013

Vinicius Anciães Darriba: professor adjunto da Universidade do Estado do Rio de Janerio, Departamento de Psicologia Clínica e Programa de Pós-Graduação em Psicanálise.

Carolina Bosse: mestre em Psicologia pela Universidade Federal do Paraná 